\title{
Stability Analysis of a Weathered-Basalt Soil Slope Using the Double Strength Reduction Method
}

\author{
Xiaoliang Liu $\mathbb{D}^{1,2}$ Xin Chen, ${ }^{1,2}$ Mei Su, ${ }^{3}$ Shilin Zhang, ${ }^{3}$ and Dengfeng Lu$^{3}$ \\ ${ }^{1}$ School of Mechanics and Civil Engineering, China University of Mining and Technology (Beijing), Beijing 100083, China \\ ${ }^{2}$ State Key Laboratory for GeoMechanics and Deep Underground Engineering, Beijing 100083, China \\ ${ }^{3}$ Liupanshui Normal University, Liupanshui 553000, China \\ Correspondence should be addressed to Xiaoliang Liu; liuxiaoliang@cumt.edu.cn
}

Received 26 December 2020; Revised 21 January 2021; Accepted 10 February 2021; Published 27 February 2021

Academic Editor: Chong Xu

Copyright ( $\odot 2021$ Xiaoliang Liu et al. This is an open access article distributed under the Creative Commons Attribution License, which permits unrestricted use, distribution, and reproduction in any medium, provided the original work is properly cited.

\begin{abstract}
Slope stability analysis of the mountain landforms in southwestern China has always been an important problem in the field of geotechnical engineering. The large landslide occurs in Jichang Town, Shuicheng County, Guizhou Province, China, on July 23, 2019, as the engineering background. Based on the nonlinear relationship between the soil water content, cohesion, and friction angle measured in laboratory tests, the finite element reduction problem of the double-strength parameters is only transformed into a reduction problem of water content. Then, based on the redevelopment platform in the ABAQUS finite element software, a user subroutine to specify predefined field variables (UFIELD) was written to numerically simulate the stability of the Jichang slope before the landslide. The results show that the Jichang slope is mainly composed of basalt-weathered red clay mixed with gravel of various particle sizes. The underlying bedrock is primarily the Permian Emeishan basalt with strong-to-weak weathering and a small amount of argillaceous siltstone. Due to the increase in water content caused by heavy rainfall, the strength of the soil decreased continuously. Once the critical stress state of the slope was exceeded, the plastic sliding block slipped at high speed over a long distance along the rock-soil layer interface, and along the way, it scraped out and carried away the original loose topsoil and gravel blocks, which finally piled up in the form of a debris flow. In addition, the attenuations of the cohesion and friction angle are different. When the water content is less than $25 \%$, the reduction coefficient of the friction angle is greater than the cohesion, which shows that the attenuation of the friction angle is stronger than that of the cohesion. The opposite is true when the water content is greater than $25 \%$. The new method of double-strength finite element reduction presented in this paper is reasonable and feasible and is more in line with the actual situation of weathered-basalt soil slope instability in heavy rainfall areas.
\end{abstract}

\section{Introduction}

Slope stability analysis has always been an important problem in the field of geotechnical engineering. Particularly in karst areas in southwestern China, the surface is generally covered by soil weathered from different rocks. The bedrock below the soil layer is mostly limestone with strong dissolution, and, in some areas, it is even composed of basalt. When the traditional limit equilibrium theory is used to analyze the slope stability, the theoretical analysis is often inconsistent with the actual situation or the prediction of the instability is inaccurate.

Since Fellenius [1] proposed the circular slide method to solve the instability of soil slopes in 1927, lots of different slope stability analysis methods have been proposed. Based on the friction circle method, Taylor [2] developed stability charts to obtain the factor of safety for a 2D purely cohesivefrictional soil slope. The methods are generally divided into traditional analysis methods and numerical analysis methods, among which the rigid body limit equilibrium method and the numerical analysis method are widely used in geotechnical engineering. The numerical analysis methods include the finite element method, the rigid body element method, the discrete element method (DEM), the equivalent continuous model, and block theory (DDA). As one of the most widely used numerical simulation methods, the finite element method plays an important role in slope engineering. The finite element law avoids the defects in the 
limit equilibrium theory, that is, that the soil should be divided into strips and assumed to be rigid bodies. Based on the existing geotechnical elastic-plastic constitutive theory, the functional relationship between the stress and deformation in rock and soil masses under an arbitrary boundary stress is simulated by calculating the stress and displacement of each node of the minimum element. To better simulate the instability process and the position of the unstable sliding surface and to calculate the safety factor of the slope, the strength reduction method can be integrated into the finite element software to solve the above problems.

Based on the traditional strength reduction method theory (SRM) proposed by Zienkiewicz [3], in recent years, Chinese and foreign scholars have researched a variety of slope stability analysis methods. The most classic example of applying strength reduction method to finite element numerical simulation is an example of homogeneous soil slope in Dawson article [4]. This example has been simulated by many scholars with a variety of numerical software. The research results all agree that the strength reduction method based on finite element is suitable for analyzing slope stability. Ugai [5], Matsui and San [6], and Griffiths and Lane [7] have conducted research on slope failure criteria. Using the strength reduction method, the reduction coefficient is continuously increased until the slope is destabilized, and the reduction coefficient at this time is defined as the safety factor of the slope. Song [8] has conducted research on dam failure criteria by the finite element strength reduction method. Zheng and Liu [9] and Liu et al. [10] have also conducted research on the applicability of various criteria including the convergence of numerical computations, the abruptness of the displacement or deformation at a certain characteristic location, and connectivity of plastic zone. Wu et al. [11] have presented a new method named dynamic method. When the slip acceleration of slope soil is equal to 0 , the slope will suffer landslide instability. Taylor [2] first suggested the adoption of different reduction factors for the cohesion and friction angle and stated that when the slope slides, the frictional resistance on the sliding surface is fully displayed first and the cohesion can then serve as the supplement. This is the original theoretical formulation of the double strength reduction method (DRM). Taylor [12] and Tang [13-15] studied the attenuation process of the shear strengths of clay and sand and concluded that the change in the water content was the main factor affecting the attenuation of the rock-soil mass parameters. Xue and Dang [16] deduced the nonequal proportional relationship between the reduction coefficient of cohesion and the reduction coefficient of the friction angle, and, finally, they carried out simulation verification using the ABAQUS software. Yuan et al. $[17,18]$ studied the proportional relationship between the two reduction factors for different slopes in combination with a computational example and provided two methods of defining the comprehensive safety factor. Xue et al. [19] established a nonproportional relationship between the cohesion reduction factor and the friction angle reduction factor for the case in which the strength parameter distribution obeys the linear attenuation assumption. Xu et al.
[20] proposed a water content variation impact-based method for determining the double strength reduction coefficient. Zhao et al. [21] and Isakov and Moryachkov [22] proposed a formula for the minimum slope comprehensive safety factor using the shortest pathway of the strength reduction. Bai et al. $[23,24]$ redefined the connotation of the double strength reduction method and used the maximum common tangent of the Mohr stress circle to solve for the final safety factor of the slope.

The above studies have enriched and developed the theoretical system of strength reduction methods, but few studies have been conducted on weathered-basalt soil slopes. Weathered-basalt soil is widely distributed in the western part of China and covers a large area of the Permian Emeishan Basalt Formation $\left(P_{2 \beta}\right)$. Due to years of geological weathering, this red soil has a high porosity, high liquid plastic limit, and high water content, and its strength varies with its water content. In particular, in the western region of Guizhou Province, China, geological disasters involving landslides of different sizes often occur. According to the statistics, nearly $30 \%$ of the geological disasters are related to weathered-basalt soil. However, due to the particularities of weathered-basalt soil slopes, little research has been conducted on this kind of slope, using either the conventional finite element strength reduction method or the double strength reduction method, which changes according to the soil strength parameters. In addition, the geomorphologic characteristics of the high mountains in Guizhou Province, China, lead to large variation in the thickness and degree of weathering of the rock masses. Therefore, it is difficult to find a typical engineering example of a weathered-basalt soil slope for stability analysis and rule summary. On July 23, 2019, a massive landslide occurred in Jichang Town, Shuicheng County, Guizhou Province, China, resulting in 43 casualties and 9 missing. According to an actual interview, the scale of the landslide was too large, and some of the bodies have been permanently buried in the landslide. To provide a theoretical basis for local landslide research, in this study, the redevelopment function in the ABAQUS finite element software was used to write a UFIELD user subroutine and to conduct numerical simulation research on the Jichang slope and analyze and evaluate the stability and safety factor of the slope.

\section{Basic Principles of the Strength Reduction Method}

2.1. Definition of the Classical Strength Reduction Coefficient. In slope stability analysis, the slope stability safety factor proposed by Bishop [1] in the limit equilibrium method was the first. Zienkiewicz et al. [3] proposed the concept of the shear strength reduction coefficient, which is essentially the same, when he studied the elastic-plastic finite element numerical analysis of soil. When the external load remains unchanged, the strength reduction coefficient is the ratio of the maximum shear strength within the slope to the actual shear stress. Among them, the maximum shear strength is calculated according to the index after reduction. Generally, based on the values of the rock-soil material parameters, that 
is, the cohesion $C$ and friction angle $\varphi$, a new set of $C$ and $\varphi$ values are obtained by dividing them by a reduction coefficient $F$. These new sets of values are taken as the parameters and are input into the finite element software for the simulation. If the safety factor at this point is greater than 1, then we continue to reduce and repeat the previous step until the calculated shear strength and shear stress ratio is 1 . That is, the slope is in a critical stress state at this time, and the reduction coefficient is the safety coefficient of the slope, as is shown in the following:

$$
\begin{aligned}
c^{\prime} & =\frac{c}{F} . \\
\varphi^{\prime} & =\arctan \left[\frac{1}{F} \tan \varphi\right] .
\end{aligned}
$$

2.2. Double Strength Reduction Factor Method. The traditional strength reduction method (SRM) is to reduce the friction angle and cohesion by the same proportion. However, Taylor [2] found that the effects of the cohesion and friction angle on the slope instability process, as well as the attenuation intensity, were significantly different. Therefore, when the slope safety factor reduction is carried out, the two parameters should be reduced to different degrees in accordance with the actual situation, which is the double strength factor reduction method (DRM). The specific expressions are as follows:

$$
\begin{aligned}
& \operatorname{SRF}_{C}=\frac{C_{0}}{C_{c r}}, \\
& \operatorname{SRF}_{\varphi}=\frac{\varphi_{0}}{\varphi_{c r}} .
\end{aligned}
$$

In (3) and (4), $C_{0}$ and $\varphi_{0}$ are the natural cohesion and friction angle of the soil mass, respectively, and $C_{c r}$ and $\varphi_{c r}$ are the cohesion and friction angle of the soil mass under the critical stress, respectively. $\mathrm{SRF}_{C}$ and $\mathrm{SRF}_{\varphi}$ are the reduction coefficients of the cohesion and friction angle, respectively, namely, the safety factor $F_{C}$ corresponding to the cohesion of the slope and the safety factor $F_{\varphi}$ corresponding to the friction angle. However, in practice, only a comprehensive safety factor value can be provided when slope stability is analyzed and evaluated. Therefore, at present, representative methods of determining the double-strength reduction factor $\mathrm{F}$ in China and abroad are in Table 1.

The weathered-basalt soil used in this study is from a special soil mass formed by weathering in southwestern China. Its parent rock is Permian basalt unique to China. Due to its large porosity, high liquid plastic limit, and high water content, the strength of the soil depends heavily on the local rainy environment. Therefore, the fourth doublestrength reduction coefficient method [20] listed in Table 1 was adopted in this study to analyze the finite element stability of the Jichang slope. Finally, the simulation results were verified by comparing them with the results of the traditional limit equilibrium method. When the functional relationship between the cohesion and friction angle of a soil mass with a certain water content is known, then the difficulty of determining the reduction coefficient of the double strength in proportion can be uniformly reduced to the problem of only using the water content of the soil mass in the critical state of the slope. That is, the cohesion and friction angle corresponding to the moisture content of the soil under the critical stress state are taken and then divided by their respective natural values to obtain their respective safety factors, $F_{C}$ and $F_{\varphi}$ (see (5) and (6)). This method is a strength reduction coefficient method that considers the changes in the soil parameters caused by the change in water content. Consider

$$
\begin{aligned}
& F_{C}=\frac{C_{0}}{C_{c r}} . \\
& F_{\varphi}=\frac{\varphi_{0}}{\varphi_{c r}} .
\end{aligned}
$$

In (5) and (6), $C_{0}$ and $\varphi_{0}$ are the natural cohesion and friction angle of the soil mass, respectively, and $C_{c r}$ and $\varphi_{c r}$ are the cohesion and friction angle of the soil mass under the critical stress for a certain water content, respectively. $F_{C}$ and $F_{\varphi}$ are the reduction coefficients of the corresponding two parameters in the critical state of the soil. Consider

$$
\begin{aligned}
& \gamma_{C}=\frac{C_{0}-C_{c r}}{C_{0}} . \\
& \gamma_{\varphi}=\frac{\varphi_{0}-\varphi_{c r}}{\varphi_{0}} . \\
& \beta_{C}=\frac{\gamma_{C}}{\gamma_{C}+\gamma_{\varphi}} . \\
& \beta_{\varphi}=\frac{\gamma_{\varphi}}{\gamma_{C}+\gamma_{\varphi}},
\end{aligned}
$$

$\gamma_{C}$ and $\gamma_{\varphi}$ are the degrees of reduction of the cohesion and friction angle relative to the natural state value in the critical state of the soil slope, respectively, and $\beta_{C}$ and $\beta_{\varphi}$ are the attenuation weight coefficients of the cohesion and friction angle, respectively. According to the fourth method of calculating the double strength reduction factor listed in Table 1, the slope safety factor $F$ can be expressed as follows:

$$
F=F_{C} \beta_{c}+F_{\varphi} \beta_{\varphi}
$$

After rearranging and substituting (5) to (10) into (11), a concrete expression for the slope safety factor $F$ value can finally be obtained:

$$
F=\frac{F_{C}+F_{\varphi}-\left(F_{C}^{2}+F_{\varphi}^{2}\right)}{2-F_{C}-F_{\varphi}} .
$$

In (12), $F_{C}$ and $F_{\varphi}$ are the reduction coefficients of the cohesion and friction angle, respectively, corresponding to the critical instability state of the soil for a certain water content, which can be obtained using (5) and (6). 
TABLE 1: Different methods of calculating the comprehensive safety factor $[14,17,20,22]$.

\begin{tabular}{lcc}
\hline Case & Scholar & Equation \\
\hline 1 & Tang & $F=F_{c}+F_{\varphi} / 2$ \\
2 & Isakov & $F=1 / 1-L_{\min }, L_{\min }=f\left(F_{c}, F_{\phi}\right)$ \\
3 & Yuan & $F=\sqrt{2} F_{c} F_{\varphi} / \sqrt{F_{c}^{2}+F_{\varphi}^{2}}$ \\
4 & Xu & $F=F_{c} \beta_{c}+F_{\varphi} \beta_{\varphi}$ \\
\hline
\end{tabular}

\subsection{Performing the ABAQUS-Based Finite Element Strength} Reduction Method. The above double strength reduction coefficient method is based on the changes in the soil parameters caused by the change in the water content in the actual situation. This method is based on the actual variations in the parameters of the soil mass. Therefore, to carry out the finite element strength reduction calculations, first field sampling and testing need to be carried out, and the different water contents corresponding to the cohesion and friction angle function relationship need to be fit; that is, $C=f(\omega)$ and $\varphi=f(\omega)$. The $C$ and $\varphi$ values corresponding to each group of water contents are calculated using finite element method successively until the critical stress state of the slope is reached. The critical stress state of the slope is characterized using the nonconvergence calculation. In this study, with the help of the redevelopment function in the ABAUQS finite element software platform, a UFIELD user material subroutine was programmed to conduct the $C$ and $\varphi$ value nonsynchronous finite element reduction calculations based on the changes in the water content. The specific calculation process is shown in Figure 1, and the program source code is detailed in Appendix A.

\subsection{Selection of the Constitutive Model and Slope Instability} Criterion. When the traditional limit equilibrium method is used to calculate the slope stability safety factor, it is assumed that the rock mass is an ideal rigid-plastic material, but this is not consistent with the constitutive relationship between the coupling effect of the rock and the elastic-plastic viscosity. In the ABAQUS software, elastoplastic, viscoelastic, or elastoplastic viscosity constitutive models can be arbitrarily adopted according to the actual situation. The redevelopment function of the user-oriented subroutines can satisfy any form of constitutive relationship. In the failure simulation of the engineering mechanical properties of geotechnical materials, the general constitutive relationships include the Mohr-Coulomb strength criterion, the Drucker-Prager strength criterion, the Griffith strength theory, and the Hoek-Brown strength criterion. The Mohr-Coulomb strength criterion is widely used because of its simple formula, its clear parameters, and its ability to reflect the properties of rocks and soils. The Mohr-Coulomb strength criterion can represent the shear strength characteristics of rocks and soils under tensile or compressive stress. However, the $\Pi$ plane and the principal stress shape of the yield surface, within the sharp corners, is a singular point. In this case, if the associated flow rule is used in the numerical simulation, then the plastic potential surface and the yield surface are the same, so the

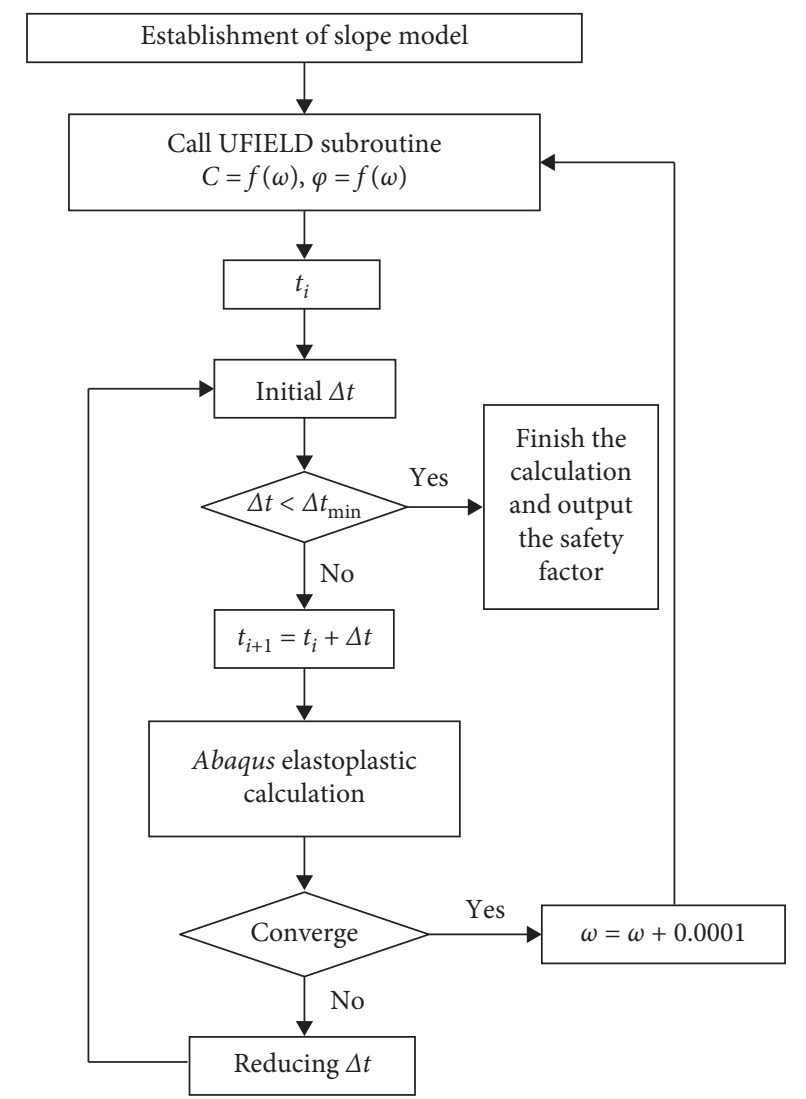

FIGURE 1: Flowchart of the nonproportional correlative reduction method used to determine the slope's double safety factors.

plastic flow direction will be uncertain at the sharp angle of the yield surface's shape. In this study, the ABAQUS software platform was used for the numerical simulation. The modified Mohr-Coulomb strength criterion is built into the software, which can make the yield surface become a continuous and smooth yield surface of an elliptical function, so the force and displacement state of the slope instability can be better simulated. In the finite element method for slope numerical analysis, different strength reduction coefficients are given in advance, and then finite element analysis is carried out according to the reduced rock and soil mass parameters. The break point of the numerical simulation is calculated as a nonconvergence. There are three ways to judge the failure of the slope. In the first method, the nonconvergence criterion of the numerical calculation is taken as the basis of the discrimination, but the accuracy of this method is closely related to the finite element calculation method and the type of element. The second is to take a characteristic point at the top or middle of the dangerous part of the slope and to distinguish the abrupt transition value of its displacement in the simulation process. The displacement value can be taken as the horizontal displacement or its equivalent displacement value. Third, whether or not a well-defined equivalent plastic shear strain zone is formed in the slope is taken as the discriminant basis. In this study, it was concluded that the safety factor value can be obtained reasonably only when all of the discriminant bases are used synthetically and are combined with the actual situation of the slope. 


\section{Geological Characteristics of the Jichang Slope}

The Jichang slope is located in Jichang Town, southern part of Shuicheng County, Liupanshui City, Guizhou Province, China. The area is on the west bank of the upstream part of the Beipan River. The mountainous elevation difference in the region is large. The highest altitude is $+2870 \mathrm{~m}$, and the lowest altitude is $+631 \mathrm{~m}$, making this a middle mountain type landform. Due to the influence of the temperate monsoon climate, the annual rainfall is high. According to statistics, the average annual precipitation is about $1100 \mathrm{~mm}$. The geological structure is characteristic of an area containing the southeastern margin of the Qinghai-Tibetan Plateau and the South China Block. Figure 2 presents a regional three-dimensional map of the topography and landforms.

There are many potential landslides and ancient landslides in the study area, and their distribution is complex. The landslide in Shuicheng County, Guizhou Province, China, on July 23, 2019, occurred on the largest of these dangerous slopes. This rare landslide killed 43 people and left 9 others missing. The slope is located $500 \mathrm{~m}$ from the southwestern part of Jichang Town; the Pingdi reservoir is located at the foot of the slope; county road X244 is at the top of the slope; and the elevation difference from the top to the foot of the slope is more than $500 \mathrm{~m}$. The total length of the landslide was more than $1.3 \mathrm{~km}$, of which the length of the slide bed was $1.1 \mathrm{~km}$, the width of the back edge was $180 \mathrm{~m}$, and the width of the leading edge was $370 \mathrm{~m}$. The overall sliding direction was NNE. The total area affected by the landslide was $374,000 \mathrm{~m}^{2}$, and the estimated landslide volume was about 2 million $\mathrm{m}^{3}$ (Figure 3 ).

The main outcrop strata of the Jichang slope are the Permian Emeishan Basalt Formation $\left(P_{2 \beta}\right)$ and the coalbearing Longtan Formation $\left(P_{2 l}\right)$ at the foot of slope. The surface is Quaternary $(Q)$ eluvial red clay formed by weathering of the basalt. The basalt is mainly composed of basaltic lava with pyroclastic rocks and tuffs. Columnar joints are developed. The rock strata trend northeast with an inclination angle of about $30^{\circ}$. The surface of the slope is covered by a soil layer of variable thickness, and the foot of the slope is a thick layer of weathered basalt laterite, which is the main medium in the landslide. The hard basalt exposed by weak weathering may be directly at the top or the waist of the slope. The weathering degree of the soil layer on the slope is not uniform. It is generally thicker in the col, but it is very thin at the top and the waist of the slope, and the basalt may even be directly exposed. Due to the steep terrain and dense vegetation coverage in the study area, it is difficult to precisely determine the specific thickness of the weatheredbasalt soil layer of the slope. Figure 4 only shows the thickness of the soil layer based on a few measurement points throughout the site, from which the thickness of the entire slope is estimated.

\section{Numerical Simulation of the Jichang Slope's Stability}

4.1. Physical-Mechanical Properties of the Rock and Soil Mass of the Jichang Slope. We conducted geological investigation and sampling work in the field and concluded that the surface layer of the Jichang slope is covered by a layer of red weathered-basalt soil, the thickness of which varies greatly. The thickness of this layer of red soil is larger at the foot of the mountain and smaller on the mountainside and at the top of the mountain. The stratigraphic lithology of the study area is basalt with different degree of successive weathering downwards, except for the strongly weathered basalt; its mechanical properties are close to the strength of soil. Moreover, the weathered basalt generally contains gravel with different particle sizes, and its strength decreases rapidly after being wet by rain.

As can be seen from Table 2, the weathered basalt laterite in this region is characterized by a large proportion of soil, a high water content, and a high plasticity. Due to the large variation in the weathering degree of basalt and the inclusion of a few small gravel blocks, the physical-mechanical properties of the highly weathered and completely weathered rock are also very different. Therefore, in this study, the laboratory tests were only conducted using strongly weathered-basalt soil samples. Figure 5 shows the consolidated undrained triaxial test results of the natural soil sample collected from the study area. For different confining pressures (i.e., $\sigma_{3}=100,200,300$, and $400 \mathrm{kPa}$ ), the stress difference when the soil sample fails increases with increasing confining pressure, indicating that as the confining pressure increases, the required failure stress of the soil sample also increases. When the confining pressure was $\sigma_{3}=400 \mathrm{kPa}, \Delta \sigma$ reached $1.73 \mathrm{MPa}$, indicating that the strength of the soil under high confining pressure was greater than that of general cohesive soil, which may be caused by the inclusion of fine sand and gravel.

Finally, the values of the internal friction and the cohesion of the soil sample were determined to be $C=32.3 \mathrm{kPa}$ and $\varphi=43.7^{\circ}$, respectively.

The soil samples were dried and ground, and the remolded soil samples were prepared using a $2 \mathrm{~mm}$ standard sieve. Before the experiment, the moisture content of the soil sample was divided into several groups at intervals of $5 \%$. According to the actual situation, the moisture content of the prepared soil sample was successively increased from 5\% to $50 \%$. Finally, the samples were subjected to direct shear tests, and the cohesion $C$ and friction angle $\varphi$ of each soil sample were calculated under different water content conditions. The results are shown in Figure 6.

The functional relationships between the water content of the soil and $C=f_{C} \omega$ and $\varphi=f_{\varphi} \omega$ were obtained through fitting:

$$
\begin{aligned}
& C=431.3 \omega^{2}-431.9 \omega+138.1, \\
& \varphi=11.3 \omega^{2}-63.6 \omega+49.6 .
\end{aligned}
$$

The underlying bedrock of the Jichang slope is mainly Emeishan Basalt Formation with different degrees of weathering, and only the argillaceous siltstone of the Longtan Formation is exposed at the foot of the slope. Basalt samples were collected, and their basic physical and mechanical properties were tested using a rock triaxial testing machine. The results are shown in Table 3. As can be seen from the table, the elastic modulus of the rock sample is 59.2 


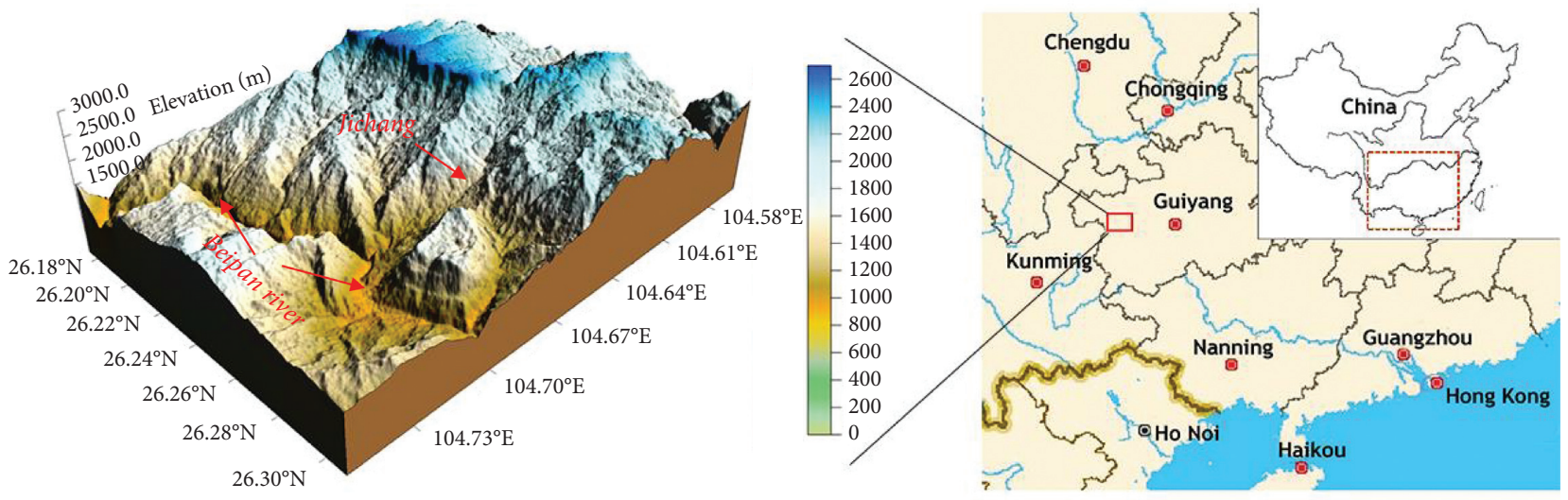

Figure 2: Topographic geomorphologic map of the study area.

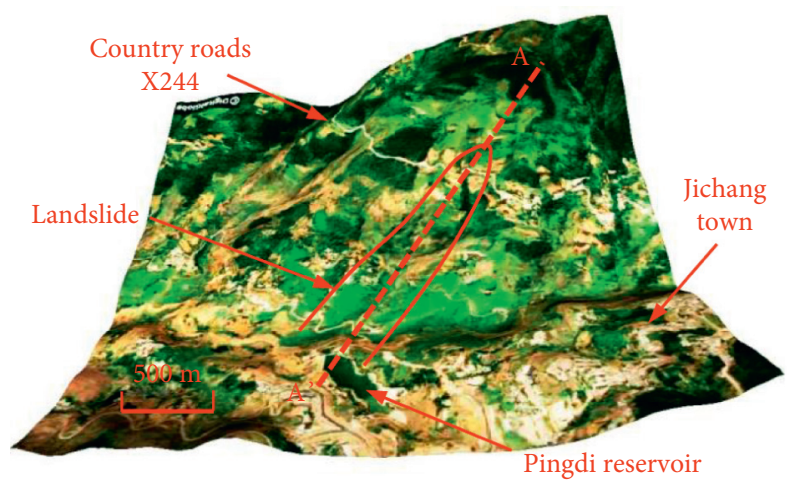

Figure 3: 3D satellite image of the Jichang slope.

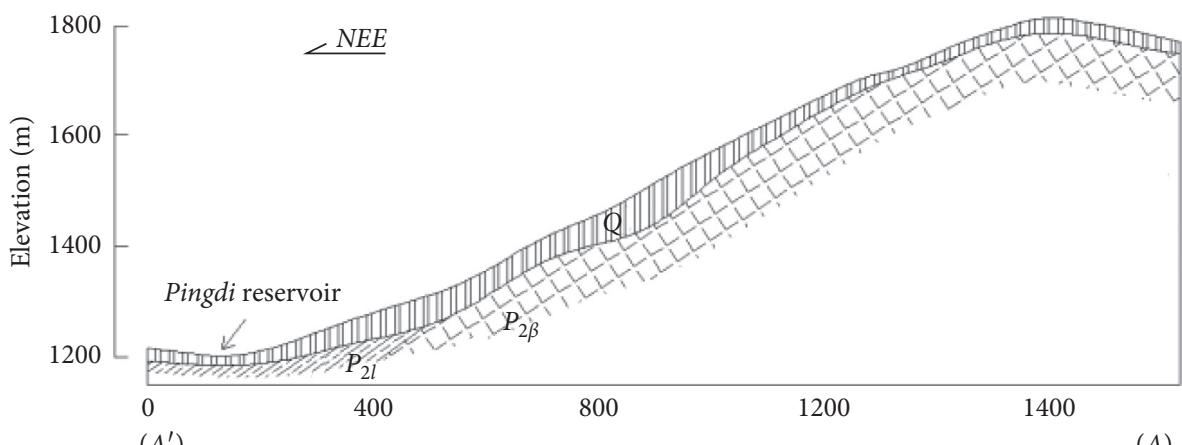

$\left(A^{\prime}\right)$

(A)

||R||| Basalt weathering soil

$P_{2 \beta}$. Strong to weakly weathered basalt

P2. Argillaceous siltstone

Figure 4: Cross section A-A' of the Jichang slope.

TABle 2: Physical-mechanical properties of the red weathered-basalt soil.

Natural density
$\left(\mathrm{g} / \mathrm{cm}^{3}\right)$ Water content (\%) Void ratio Liquid limit (\%) Plastic limit (\%) Plasticity index Cohesion (kPa) Friction angle $\left({ }^{\circ}\right)$ 


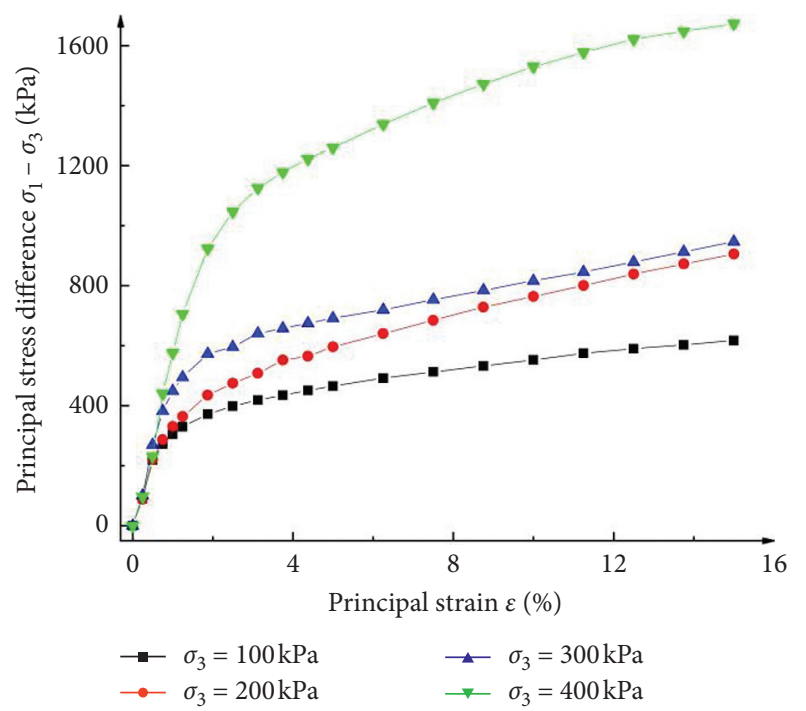

FIGURE 5: Stress-strain relationship obtained from the consolidated undrained triaxial test of the soil samples.

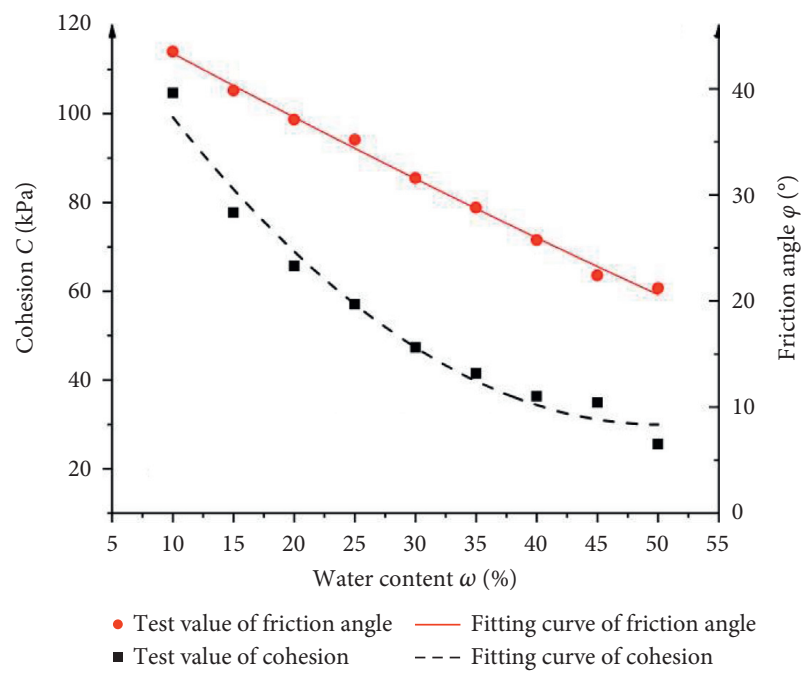

FIgURE 6: The relationships between the shear strength parameters and the water content.

$\mathrm{GPa}$ and its uniaxial compressive strength is $184 \mathrm{MPa}$. The rock sample has a high-elastic modulus and is a highstrength rock. By observing the rocks in the field, it was determined that the basalt rocks in this area are characterized by a very dense lithology, with columnar joints developed and occasional almond-shaped pores. Generally, the strength of the highly weathered rocks is still very high, and the cracks in the surface rocks are relatively welldeveloped.

4.2. Numerical Simulation of Slope Stability. According to the test results, in this study, the UFIELD subroutine in the ABAQUS finite element software platform was used to analyze the stability of the Jichang slope based on the double strength reduction principle with the influence of a changing water content given above. UFIELD is the abbreviation of user subroutine to specify predefined field variables. It allows user to prescribe predefined field variables at the nodes of a model-the predefined field variables at a node can be updated individually, or a number of field variables at the node can be updated simultaneously. Compared with the traditional limit equilibrium method, the strength reduction finite element method has the advantage that the position and shape of the sliding surface do not need to be set artificially. By proportionally decreasing the rock mass parameters, when the shear strength of the rock mass cannot resist the external load, the slope will become unstable and fail. In addition, the excellent postprocessing function in the ABAQUS finite element software was used to simulate the specific position of the slope when it fails to stabilize and the change in the load displacement during the failure process.

The surface of the slope is covered by a soil layer of variable thickness, and the foot of the slope is a thick layer of weathered basalt laterite, which is the main medium in the landslide. The hard basalt exposed by weak weathering may be directly at the top or the waist of the slope. The weathering degree of the soil layer on the slope is not uniform (see Figure 2). Considering the high strength mechanical properties of basalt comprehensively, this numerical simulation test only carries on the double strength reduction numerical calculation of the surface basalt weathering red soil of Jichang slope. Through the National Geospatial Data Cloud Platform of China, the satellite elevation data in Jichang Town area was downloaded, and the Surfer software was used to generate the $3 \mathrm{D}$ terrain geomorphological map of the region (as shown in Figure 2). Then, select a section at the location of the landslide on the topographic map, extract the section elevation data, and import it into ABAQUS software for modeling. The model constitutive relation is based on the extended Mohr-Coulomb strength criterion. The model adopts two-dimensional plane strain, and the integral form is not diminished. The numerical simulation flowchart is shown in Figure 1.

\section{Results}

Figures 7 and 8 show the plastic strain cloud maps at different moments during the numerical simulation. As can be seen, at $t=0.312 \mathrm{~s}$, due to the long and steep slope distance, two plastic strain zones formed at different positions of the slope's surface, but the plastic strain was small at this time. As the numerical simulation progressed, the two plastic zones continued to expand downward and gradually changed into a plastic slip zone along the soil-rock interface layer. At this time, the main slip surface of the slope was at the rock-soil layer. At $t=0.624 \mathrm{~s}$, the slope was in a state of critical stress, and the two plastic zones converged at the rock-soil interface layer. At this time, the plastic zone extending downward from the slope surface connected with the plastic zone on the rock-soil interface layer, forming an overall open plastic slip zone, and the slope suffered landslide instability (Figure 8). As can be seen from the figure, at this time, the maximum plastic strain at the rock-soil interface was 0.158 , which indicates that the main sliding surface of the Jichang landslide was the rock-soil interface. 
TABle 3: Physical-mechanical properties of the rocks.

\begin{tabular}{lccccccc}
\hline Lithology & $\begin{array}{c}\text { Natural } \\
\text { density } \\
\left(\mathrm{g} / \mathrm{cm}^{3}\right)\end{array}$ & $\begin{array}{c}\text { Young's } \\
\text { modulus }(\mathrm{GPa})\end{array}$ & $\begin{array}{c}\text { Poisson's } \\
\text { ratio }\end{array}$ & $\begin{array}{c}\text { Uniaxial compressive } \\
\text { strength }(\mathrm{MPa})\end{array}$ & $\begin{array}{c}\text { Indirect tensile } \\
\text { strength }(\mathrm{MPa})\end{array}$ & $\begin{array}{c}\text { Cohesion } \\
(\mathrm{MPa})\end{array}$ & $\begin{array}{c}\text { Friction } \\
\text { angle }\left({ }^{\circ}\right)\end{array}$ \\
\hline $\begin{array}{l}\text { Basalt } \\
\begin{array}{l}\text { Argillaceous } \\
\text { siltstone }\end{array}\end{array}$ & 2.97 & 59.2 & 0.18 & 184 & 27.9 & 32.3 \\
\hline
\end{tabular}

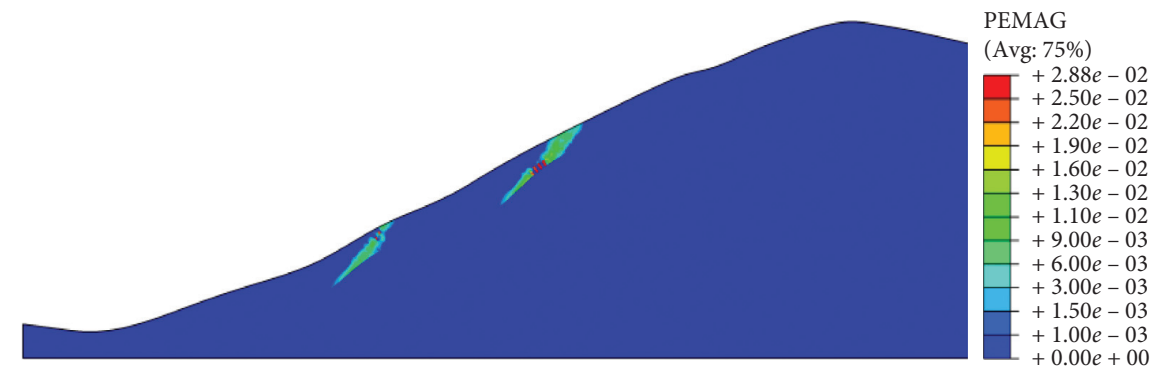

Figure 7: Plastic strain cloud map of the slope at $t=0.312 \mathrm{~s}$.

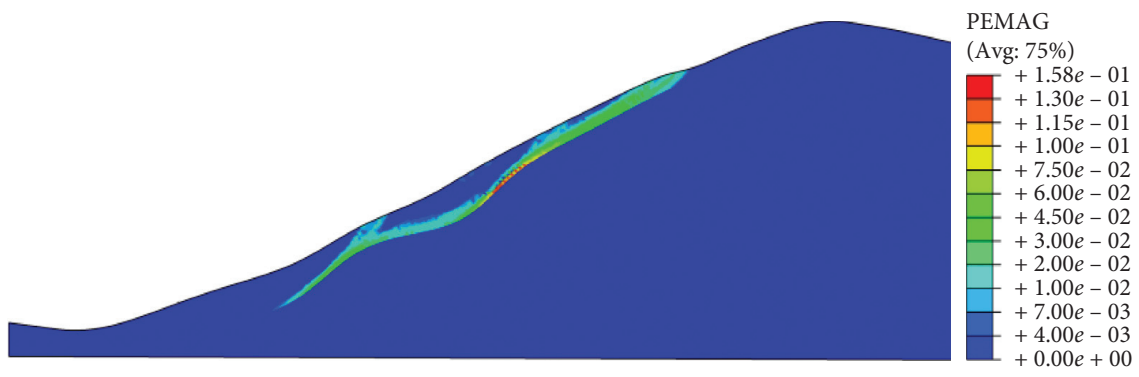

Figure 8: Plastic strain cloud map of the slope at the critical strength at $t=0.624 \mathrm{~s}$.

Due to the continuous heavy rainfall in the study area, the strength parameters of the weathered-basalt soil with different surface cover thicknesses decreased, which finally led to the occurrence of a landslide. According to the numerical simulation analysis, this type of slope is different from a general soil slope. The plastic slip zone of a general soil slope will extend from the slope surface to the slope foot, leading to the instability of the entire slope. The failure mechanism of this type of slope is that as long as the plastic slip zone is connected with the outside world, forming an open slip block, the slope will undergo failure. Thus, due to the difference in the slope's profile structure and the geotechnical physical properties, the plastic slip zone is not connected to the foot of the slope. Instead, it is connected to the outside at a position in the middle of the slope (Figure 8), and its main sliding surface is the plane of the rock-soil interface.

Figure 9 shows the equivalent displacement cloud map the slope at the critical stress at $t=0.667 \mathrm{~s}$. As can be seen, a large displacement zone is formed in the middle of the slope, where the maximum displacement is $2.45 \mathrm{~m}$. The slip zone location of the numerical simulation test is the same as the actual location, which is near county road X244 on the upper part of the slope. As can be seen, the location is an important source area of the landslide and has been verified that the numerical simulation result is consistent with the evolution characteristics of the actual landslide. After the plastic slip zone is formed in the loose soil in the source area, the high slope is formed because of the great elevation difference. The plastic slip zones were formed on the slope's surface. Then, the slip zones continuously expanded, and, finally, they connected with the plastic slip zone at the rock-soil interface, forming an open plastic slip block. When the critical stress state of the slope exceeded a certain value, the slippage mass migrated along the rock-soil interface for a long distance, scraping up the clastic soil along the migration path and forming a high-speed clastic flow landslide. This clastic flow landslide body was deposited at the foot of the slope on the side of Pingdi reservoir after being transported for nearly 1000 meters. Through an investigation of the landslide disaster, it is found that a large number of houses buried by the landslide are just above the migration path of the sliding body in the numerical simulation, and the location of the source area is consistent with the numerical simulation results. These conclusions confirm the rationality of the simulation results of the Jichang slope in this paper. 


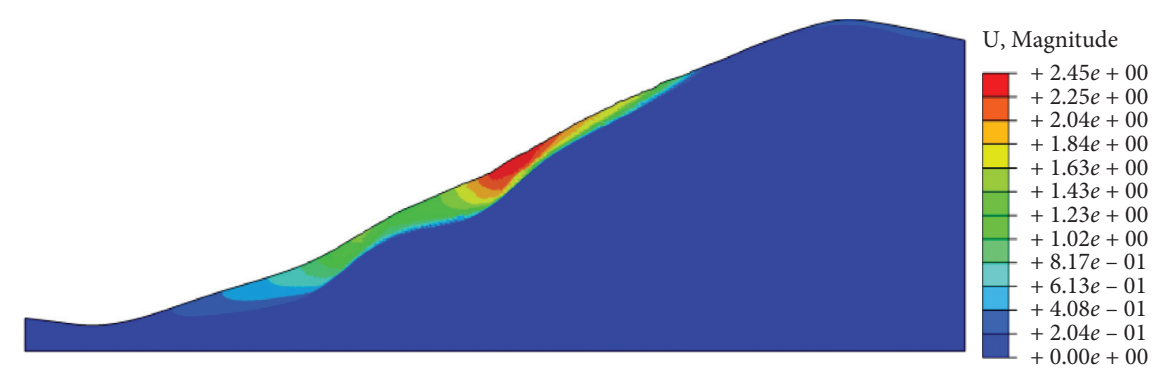

Figure 9: Cumulative equivalent displacement cloud map of the slope at the critical stress at $t=0.667 \mathrm{~s}$.

\section{Discussion}

The simulation calculations revealed that when the moisture content was $33.8 \%$, the Jichang slope was just entering the critical stress state. At this time, the critical cohesion of the soil was $41.4 \mathrm{kPa}$, the critical friction angle was $29.4^{\circ}$, and their respective reduction coefficients were $F_{C}=1.37$ and $F_{\varphi}=1.16$. Using (12), the double strength reduction coefficients was calculated to be $F=1.31$ (Figure 10); that is, the safety factor value of the final slope was 1.31 .

It should be noted that the double strength reduction factor $F$ is calculated by (12), which is a comprehensive reflection of the nonlinear attenuation of the cohesion and friction angle synchronously. This value can be used to represent the final safety factor of the slope. In addition, the traditional finite element strength reduction method was used in the numerical calculation of the Jichang slope, and the safety factor was determined to be $F_{\text {tra }}=1.33$. The limit equilibrium method was used to calculate the safety factor (1.36). Figure 10 shows that horizontal displacement value of the characteristic points on the slope gradually increases under different reduction coefficients varied with the field variable. The abrupt displacement point in these curves is the required reduction coefficients, which are used as the safety factor of the slope's stability. In this paper, the double strength reduction coefficient $F$ is used as the safety factor of the Jichang slope's stability. It was found that the difference between the three methods is small, and the results of this study are conservative.

As can be seen from Figure 11, as the water content increased, the degrees of the reduction of the cohesion and friction angle were different for the type of weather-basalt soil slope in Jichang Town. When the water content was less than $25 \%$, the reduction coefficient of the friction angle was greater than the reduction coefficient of the cohesion, and when the water content was greater than $25 \%$, the result was the opposite. The reason for this is that the increase in the water content caused by rainfall infiltration accelerated the softening and hydrolysis of the sliding surface soil and thus reduced the shear strength of the sliding surface soil. From the point of view of micromechanics, the cohesion is a reflection of the linking force between the particles and the capillary water in the soil. As the water content increases, the thickness of the weakly bonding water zone in the soil particles increases, and the linking force between the bonding water and the capillary water weakens. Then, the cohesion decreases on the macroscopic level. At the same

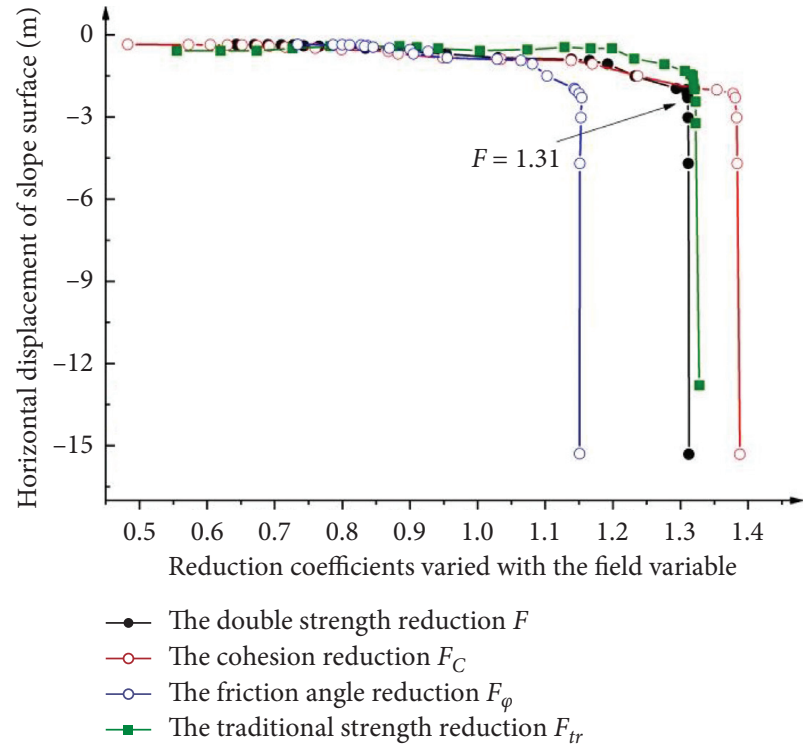

FIGURE 10: Horizontal displacement curve of the characteristic points on the slope under different reduction coefficients varied with the field variable.

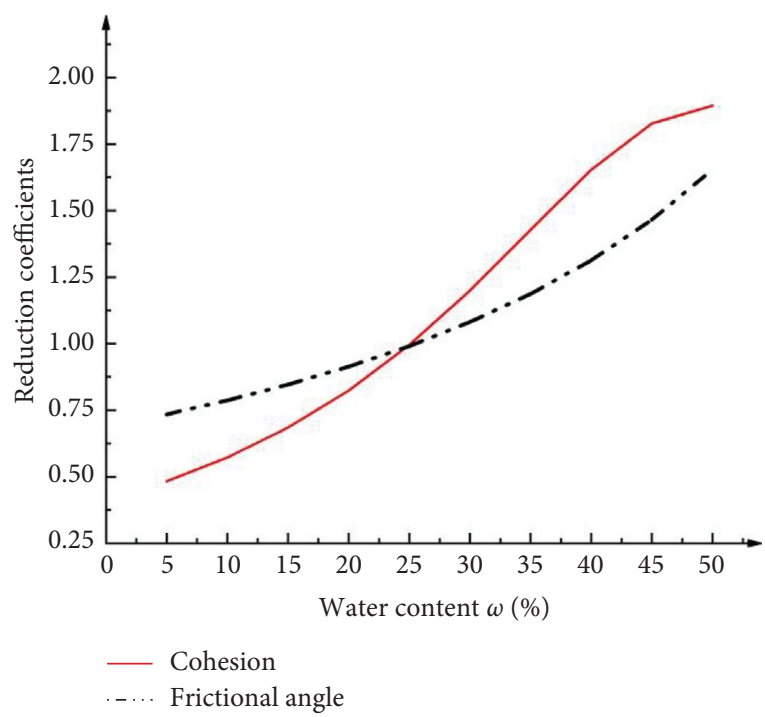

Figure 11: The variations in the reduction coefficients of the cohesion and friction angle with water content. 
time, as the thickness of the bonding water zone increases and the spacing between the soil particles increases, the mutual biting force between the particles is effectively reduced, and sliding or rolling of the particles becomes easier, which is manifested as a decrease in the friction angle on the macroscopic level. Moreover, an increase in the thickness of the bonding water zone is more likely to result in a reduction of the particle linking force. The results show that the reduction of the biting force between the particles is delayed compared with the reduction in the bonding water or capillary water. Therefore, as the water content increases, the cohesion and the friction angle do not decay synchronously, and the cohesion decreases more rapidly. For the weatheredbasalt soil slope investigated in this study, the inflection point where the decay rate of the cohesion exceeds the decay rate of the friction angle occurred at a water content of about 25\% (Figure 11).

\section{Conclusions}

(1) According to the actual functional relationships between the soil moisture content and the cohesion and friction angle of a slope, the two soil strength parameters were reduced to calculate a finite element strength reduction that truly reflects the soil strength attenuation process. After this, based on the redevelopment platform in the ABAQUS software, a UFIELD user subroutine was written. The stability of the slope was numerically analyzed using the new double-strength reduction coefficient method based on the change in the water content. The calculation results show that the safety coefficient of the Jichang slope was 1.31, and the rationality of the simulation results was verified by comparing the calculated values with those obtained using the limit equilibrium method.

(2) The Jichang slope is an unstable mixed soil-rock slope composed of weathered-basalt soil and basalt with different degrees of weathering, and it was a high-debris flow landslide. The main sliding surface of the Jichang slope was the rock-soil interface, which is quite different from the characteristics of the circular arc plastic sliding surface generated by homogeneous soil slopes. The simulation results are consistent with the actual migration of the slope in the disaster site, which also verifies that the doublestrength reduction finite element method based on the influences of water content changes on the soil strength parameters presented in this paper is effective. Moreover, this method is also suitable for analyzing the stability of the mixed high-drop slopes composed of weathered-basalt soil in southwestern China.

(3) There are intrinsic functional relationships between the water content and the soil strength parameters. As the water content increased, the cohesion and internal friction angle did not decay synchronously with time, and the cohesion decreased more rapidly.
For this weathered-basalt soil slope, the inflection point where the decay rate of the cohesion exceeded the decay rate of the friction angle occurred at a water content of about $25 \%$. However, the natural moisture content of the soil in the study area was $28.8 \%$, which indicates that the attenuation of the cohesion is the most sensitive to the contribution of the soil slope instability during continuous heavy rainfall. Although the attenuation of the friction angle was slightly delayed, there is no doubt that the attenuation of the friction angle caused by rainfall was the greatest contributor to the soil slope instability. The results of this study provide a theoretical reference for the prevention and control of local frequent landslide disasters.

\section{Appendix}

This UFIELD user subroutine can perform a nonlinear reduction of cohesion and friction angle by changing the water content $\omega$ and finally can output the reduction coefficients of cohesion and friction angle and the comprehensive slope safety factor. The subroutine source code is based on ABAQUS software interface and can allow user to prescribe predefined field variables at the nodes of a model, and the predefined field variables at a node can be updated individually, or a number of field variables at the node can be updated simultaneously. Before running the subroutine, the field variables need to be set in the .Inp file. See the subroutine source code below:

\section{!DIR\$ FREEFORM}

SUBROUTINE UFIELD(FIELD, KFIELD, NSECPT, KSTEP, KINC, TIME, NODE,\&

$$
\begin{aligned}
& \text { COORDS, TEMP, DTEMP, NFIELD) } \\
& \text { INCLUDE 'ABA_PARAM.INC' } \\
& \text { DIMENSION FIELD(NSECPT, NFIELD), TIME(2), } \\
& \text { COORDS(3), TEMP(NSECPT),\& } \\
& \text { DTEMP(NSECPT) }
\end{aligned}
$$

! Assign values to parameters

Xomegaini $=0.5$ ! Initial value of moisture content $\omega$

Xvar $=\operatorname{TIME}(2) !$ Independent variable dependent on moisture content

! Reduced by the change in the field variable.

! Predefined field variables is the initial value of moisture content, ! otherwise the value varies with $\Delta \mathrm{t}$, it has an accuracy of 0.0001

$$
\begin{aligned}
& \text { IF }(\text { Xvar } \leq 1) \text { THEN } \\
& \quad \operatorname{FIELD}(1,1)=\text { Xomegaini } \\
& \text { ELSE IF }(\text { Xvar }>1) \text { THEN } \\
& \quad \text { FIELD }(1,1)=1.5^{*}(\text { Xvar-1)+Xomegaini } \\
& \text { END IF }
\end{aligned}
$$$$
\text { RETURN }
$$$$
\text { END }
$$ 
! Extact the user-defined numbers of solution-dependent state variables

SUBROUTINE USDFLD (FIELD, STATEV, PNEWDT, DIRECT, T, CELENT, \&

TIME, DTIME, CMNAME, ORNAME, NFIELD, NSTATV, NOEL, NPT, LAYER,\&

KSPT, KSTEP, KINC, NDI, NSHR, COORD, JMAC, JMATYP, MATLAYO, LACCFLA)

INCLUDE 'ABA_PARAM.INC'

CHARACTER $* 80$ CMNAME, ORNAME

CHARACTER $* 3$ FLGRAY(15)

DIMENSION FIELD(NFIELD), STATEV(NSTATV), $\operatorname{DIRECT}(3,3), \mathrm{T}(3,3), \operatorname{TIME}(2)$

DIMENSION ARRAY(15), JARRAY(15), JMAC( * ), $\operatorname{JMATYP}(*), \operatorname{COORD}(*)$

Xvar $=\operatorname{TIME}(2)$ ! Independent variable dependent on moisture content

IF (Xvar $\leq 1)$ THEN

$\operatorname{STATEV}(1)=0$

$\operatorname{STATEV}(2)=0$

$\operatorname{STATEV}(3)=0$

ELSE IF (Xvar > 1) THEN

! Output the reduction coefficient of cohesion $\mathrm{C}$ and friction angle $\varphi$, respectively

$\operatorname{STATEV}(1)=(431.3 *(\mathrm{Xvar}-1) * * 2-431.9 *($ Xvar-

1) +138.1$) / 32.3$

$\operatorname{STATEV}(2)=(11.3 *($ Xvar- -1$) * * 2-63.6 *($ Xvar-

1) + 49.6)/43.7

! Output the double strength reduction coefficients $\mathrm{F}$ $\operatorname{STATEV}(3)=(\operatorname{STATEV}(1)+\operatorname{STATEV}(2)-$

$(\operatorname{STATEV}(1) * * 2+\operatorname{STATEV}(2) * * 2)) /(2-\operatorname{STATEV}(1)-$

$\operatorname{STATEV}(2))$

END IF

! Extract the plastic strain magnitude

CALL GETVRM ('PE', ARRAY, JARRAY, FLGRAY, JRCD, JMAC, JMATYP, MATLAYO, LACCFLA)

STATEV $(4)=\operatorname{ARRAY}(1)$

RETURN

END

\section{Data Availability}

The data used to support the findings of this study are available from the corresponding author upon request.

\section{Conflicts of Interest}

The authors declare that they have no conflicts of interest.

\section{Acknowledgments}

This study was sponsored by the Youth Science and Technology Talent Growth Project of the Education Department of Guizhou Province (no. Qian Jiao He KY Zi [2019], 127 ${ }^{\text {th }}$, and no. Qian Jiao He KY Zi [2017], 262 ${ }^{\text {th }}$ ) and Liupanshui Key Laboratory Project (no. 52020-2019-05-03). The financial support provided by these sponsors is greatly appreciated.

\section{References}

[1] A. W. Bishop, "The use of the slip circle in the stability analysis of slopes," Géotechnique, vol. 5, no. 1, pp. 7-17, 1955.

[2] D. W. Taylor, "Stability of earth slopes," Journal of the Boston Society of Civil Engineers, vol. 24, no. 3, pp. 197-246, 1937.

[3] O. C. Zienkiewicz, C. Humpheson, and R. W. Lewis, "Associated and non-associated visco-plasticity and plasticity in soil mechanics," Géotechnique, vol. 25, no. 4, pp. 671-689, 1975.

[4] E. M. Dawson, W. H. Roth, and A. Drescher, "Slope stability analysis by strength reduction," Géotechnique, vol. 49, no. 6 , pp. 835-840, 1999.

[5] K. Ugai, "A method of calculation of total safety factor of slope by elasto-plastic FEM," Soils and Foundations, vol. 29, no. 2, pp. 190-195, 1989.

[6] T. Matsui and K.-C. San, "Finite element slope stability analysis by shear strength reduction technique," Soils and Foundations, vol. 32, no. 1, pp. 59-70, 1992.

[7] D. V. Griffiths and P. A. Lane, "Slope stability analysis by finite elements," Géotechnique, vol. 49, no. 3, pp. 387-403, 1999.

[8] E. X. Song, "Finite element analysis of safety factor for soil structures," Chinese Journal of Geotechnical Engineering, vol. 19, no. 2, pp. 1-7, 1997.

[9] H. Zheng and D. F. Liu, "Properties of elastoplastic matrix Dep and a criterion on limiting state of slope stability by FEM," Chinese Journal of Rock Mechanics and Engineering, vol. 24, no. 7, pp. 1099-1105, 2005.

[10] J. L. Liu, M. T. Luan, and S. F. Zhao, "Discussion on criteria for evaluating stability of slope in elastoplastic FEM based on shear strength reduction technique," Rock and Soil Mechanics, vol. 26, no. 8, pp. 1345-1348, 2005.

[11] C. Q. Wu, Y. W. Zhu, and Y. Q. Cai, "Dynamic method to assess critical state of slope stability," Rock and Soil Mechanics, vol. 26, no. 5, pp. 784-788, 2005.

[12] D. W. Taylor, Fundamentals of Soil Mechanics, John Wiley \& Sons, New York, NY, USA, 1948.

[13] F. Tang, Y. R. Zheng, and S. Y. Zhao, "Discussion on two safety factors for progressive failure of soil slope," Chinese Journal of Rock Mechanics and Engineering, vol. 26, no. 7, pp. 1402-1407, 2007.

[14] F. Tang and R. Zheng, "Mechanism analysis of dual reduction factors about the progress failure of slope," Chinese Journal of Underground Space and Engineering, vol. 4, no. 3, pp. 436441, 2008.

[15] F. Tang and R. Zheng, "Analysis of safety reserve of slope with two strength reduction factor," Journal of Chongqing Jiaotong University. Natural Science, vol. 26, no. 4, pp. 95-100, 2007.

[16] H. B. Xue and F. N. Dang, "Research on method of slope strength parameters non-proportional associated reduction," 
Chinese Journal of Rock Mechanics and Engineering, vol. 34, no. supplement 2, pp. 4005-4012, 2015.

[17] W. Yuan, B. Bai, X.-C. Li, and H.-B. Wang, "A strength reduction method based on double reduction parameters and its application," Journal of Central South University, vol. 20, no. 9, pp. 2555-2562, 2013.

[18] W. Yuan, Study on Strength Reduction Method, Institute of Rock and Soil Mechanics, Chinese Academy of Sciences, Wuhan, China, 2014.

[19] H. B. Xue, F. N. Dang, X. Yin et al., "Nonproportional correlative reduction finite element method for slope strength parameters," Mathematical Problems in Engineering, vol. 2016, Article ID 2725354, 10 pages, 2016.

[20] X. Q. Zhao, A. M. Gong, X. Q. Xu et al., "Double strength reduction method-based study on red clay slope under consideration of impact from water content variation," Water Resources and Hydropower Engineering, vol. 51, no. 9, pp. 181-186, 2020.

[21] L. H. Zhao, J. Y. Cao, G. P. Tang et al., "Discussion on slope stability analysis with double strength reduction technique," Rock and Soil Mechanics, vol. 35, no. 10, pp. 2977-2984, 2014.

[22] A. Isakov and Y. Moryachkov, "Estimation of slope stability using two-parameter criterion of stability," International Journal of Geomechanics, vol. 14, no. 3, Article ID 06014004, 2014.

[23] B. Bai, W. Yuan, and X. C. Li, "A new double reduction method for slope stability analysis," Journal of Central South University, vol. 21, no. 3, pp. 1158-1164, 2014.

[24] B. Bai, W. Yuan, S. Lu et al., "Comparing a new double reduction method to classic strength reduction method for slope stability analysis," Rock and Soil Mechanics, vol. 36, no. 5, pp. 1275-1281, 2015. 